\title{
The Study on Static Force Behavior of Concrete Filled Steel Tube Lattice Wind Turbine Tower Joints
}

\author{
Fei Zhou ${ }^{1, a,{ }^{*}}$, Ping Huang ${ }^{2, b}$, Lujia Yang ${ }^{3, c}$ and Junfeng Yang ${ }^{4, c}$ \\ 1,2,3,4 Leshan Vocational \& Technical college, Le Shan, Sichuan province. China

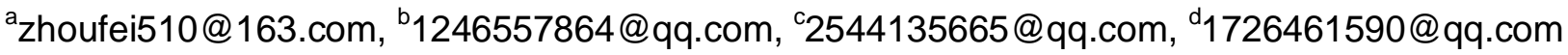

\begin{abstract}
Keywords: concrete filled steel tubular, tower, joints, finite element, equivalent stress.
Abstract. In order to discuss the failure mechanism of concrete filled steel tube lattice wind turbine tower joints. Based on the parameters of abdomen strut section form, and using nonlinear static numerical simulation, this article research on the stressed complex joints. The results of the study show that the abdominal rod for circular steel tubes node (JD1) is the local buckling of compressive bar that causes instability and failure; The abdominal rod for single angle steel (JD2) or double angle steel (JD3) node is local buckling instability that cause the failure of node board. Under the abdomen stem and node board all meeting their own capacity requirements, JD1 is very easy to make draw bar broken on both sides of the pillar tube wall region, JD2 and JD3 are apt to damage on the weak positions of node board ends and pillar tube wall joint. In the three web members node form, the highest ultimate bearing capacity is JD1 and JD3 is the second and JD2 is minimum.
\end{abstract}

\section{Introduction}

With increasing wind turbine power generation capacity, the height of wind generator tower and the top weight of the tower have gradually increased, but current using the cone cylindrical towers occupation large land area, easy unstable failure, low reliability problems made hard development of cone cylindrical towers in height, so people begin to reconsider the type of tower structure [1].

This article recommends using lattice-type concrete filled steel tubular wind generator tower instead of the traditional cone cylindrical towers whose nodes are important components and force more complex, and so far the research of this aspect is less. This article by means of a finite element simulation of lattice type steel concrete numerical simulation of wind turbine tower nodes, so as to arrive at the node failure modes, web members section of form change and its impact on the bearing capacity of the node, selecting optimal structure, providing the basis data for the current design of a wind turbine tower, promoting the development of wind power industry.

\section{Node Design}

Base on the geometric parameters and the load characteristic parameters of Inner Mongolia Bayan Obo region 1.5 MW wind generators tower type cones, design lattice-type concrete filled steel tubular tower of wind turbine, also design the form of web members section, mechanics, and other parameters of node [2]. Fig. 1 is the simplified side of lattice-type concrete filled steel tubular tower of wind turbine, and the form of tower cross-section is an equilateral triangle, height of $62.4 \mathrm{~m}$, top size $2.7 \mathrm{~m}$, taking the one-tenth of tower as bottom size, sloping of the tower 35.8 percent. 
Lattice-type concrete filled steel tubular wind turbine tower is divided into 21 layers, taking node between 11 and 12 layer as shown in Fig. 2, and its physical parameters are provided in table 1 [3].

\begin{tabular}{|c|c|c|c|c|c|c|c|c|c|c|}
\hline \multirow[b]{2}{*}{$\begin{array}{c}\text { node } \\
\mathrm{n}\end{array}$} & \multicolumn{3}{|c|}{ cross section parameter(mm) } & \multicolumn{3}{|c|}{ steel type } & \multicolumn{3}{|c|}{ size $(\mathrm{mm})$} & \multirow{2}{*}{$\begin{array}{l}\text { concret } \\
\text { e } \\
\text { Tower } \\
\text { column }\end{array}$} \\
\hline & $\begin{array}{l}\text { Tower } \\
\text { column }\end{array}$ & $\begin{array}{c}\text { Slant } \\
\text { rod }\end{array}$ & $\begin{array}{c}\text { Cross } \\
\text { bar }\end{array}$ & $\begin{array}{c}\text { Tower } \\
\text { colum } \\
n\end{array}$ & $\begin{array}{c}\text { Slant } \\
\text { rod }\end{array}$ & $\begin{array}{c}\text { Cross } \\
\text { bar }\end{array}$ & $\begin{array}{l}\text { Tower } \\
\text { colum } \\
\mathrm{n}\end{array}$ & $\begin{array}{l}\text { Slan } \\
\mathrm{t} \text { rod }\end{array}$ & $\begin{array}{l}\text { Cros } \\
\text { s bar }\end{array}$ & \\
\hline JD1 & $\varphi 400 \times 8$ & $\varphi 127 \times 6$ & $\varphi 127 \times 6$ & $\begin{array}{c}\text { Q345 } \\
\text { D }\end{array}$ & $\begin{array}{c}\text { Q235 } \\
\text { D }\end{array}$ & $\begin{array}{c}\text { Q235 } \\
\text { D }\end{array}$ & 3000 & $\begin{array}{c}130 \\
0\end{array}$ & 1100 & $\mathrm{C} 40$ \\
\hline JD2 & $\varphi 400 \times 8$ & $\begin{array}{c}\mathrm{L} 100 \times 1 \\
2\end{array}$ & $\begin{array}{c}\mathrm{L} 100 \times 1 \\
2\end{array}$ & $\begin{array}{c}\text { Q345 } \\
\text { D }\end{array}$ & $\begin{array}{c}\text { Q235 } \\
\text { D }\end{array}$ & $\begin{array}{c}\text { Q235 } \\
\text { D }\end{array}$ & 3000 & $\begin{array}{c}130 \\
0\end{array}$ & 1100 & $\mathrm{C} 40$ \\
\hline JD3 & $\varphi 400 \times 8$ & $\begin{array}{c}2 \mathrm{~L} 100 \times \\
6\end{array}$ & $\begin{array}{c}2 \mathrm{~L} 100 \times \\
6\end{array}$ & $\begin{array}{c}\text { Q345 } \\
\text { D }\end{array}$ & $\begin{array}{c}\text { Q235 } \\
\text { D }\end{array}$ & $\begin{array}{c}\text { Q235 } \\
\text { D }\end{array}$ & 3000 & $\begin{array}{c}130 \\
0\end{array}$ & 1100 & $\mathrm{C} 40$ \\
\hline
\end{tabular}

Table 1,Specimen's parameters

Note: when the work of temperature below -20 $\square$, Q235D grade steel and Q345D grade steel should be use [4]

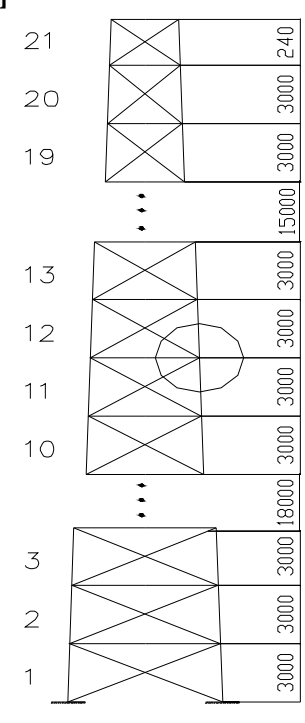

Fig. 1,Tower simplified side figure

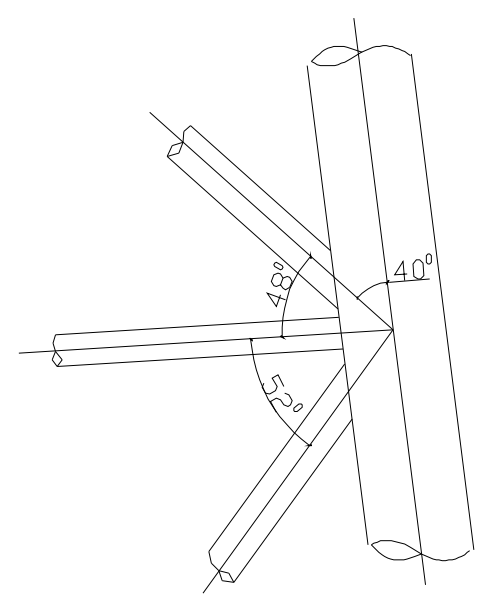

Fig. 2,Typical joint

\section{The relation of material constitutive selection}

Steel is the ideal elastic-plastic materials, when finite element simulation analysis on nodes, using trilinear model, as shown in Fig. 3. Because of concrete materials own characteristics, its determine the nonlinear of inhomogeneity and stress-strain relationship of concrete material composition, in concrete-filled steel tube, if you provide enough binding for the core concrete-filled steel tube, with the increase of deformation, stress-strain curve of concrete will not decline; Conversely, if you cannot provide enough binding for the core concrete-filled steel tube, stress-strain curve of concrete will decline. When this article using finite element analyze the node of concrete-filled steel tube, using of core concrete stress-strain relationship model of the tower pillar consider the constraint effect of concrete-filled steel tubular stress-strain relations model [5] , as shown in Fig. 4. 


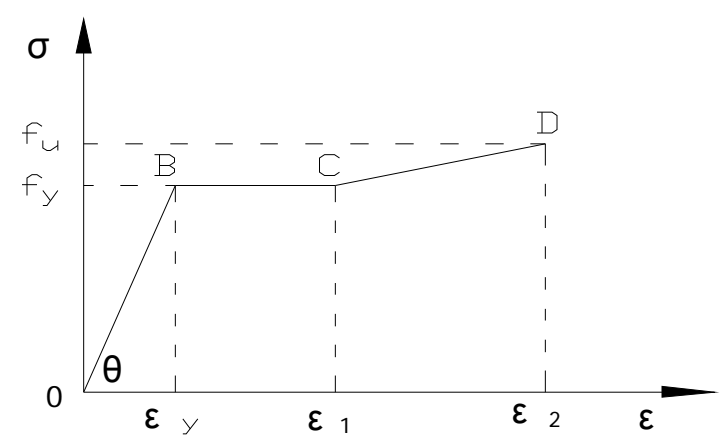

Fig. 3, Steel constitutive relation

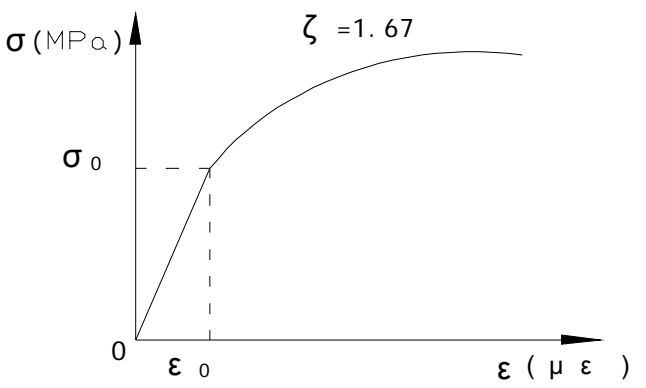

Fig. 4,Stress-strain relationships of concrete

\section{The contacted relationship treatment}

Contact properties include two parts: the interface between the normal function and tangential role.

For normal function, the default relationship of contact pressure and clearance of the ABAQUS is "hard contact" that means the size of the transitive contact pressure in the interface without restriction, when the pressure becomes zero or negative, separation of two contact interface and remove contact constraints on the corresponding node [6]; For tangent role, friction model often use in ABAQUS which is coulomb friction, friction coefficient to represent the contact surface between friction characteristics is using the friction coefficient to express the properties of interface. The friction coefficient of steel tube and concrete interfacial is range from 0.2 to 0.6 [7], by trial calculation of friction coefficient having little impact on results and this article taking 0.4.

\section{Element type and mesh generation}

The finite element model of steel pipe, concrete, rigid covers plate all use eight-node reduced integration scheme of three dimensional solid elements, the mesh as shown in Fig. 5-7.

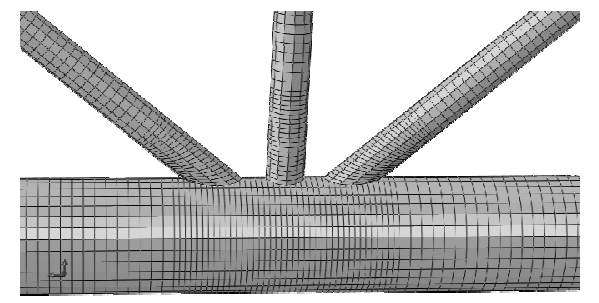

Fig. 5,Meshing of JD1

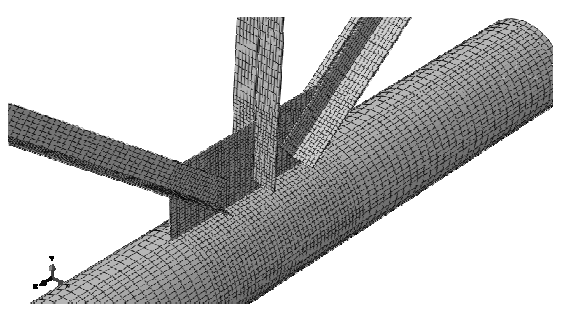

Fig. 7,Meshing of JD3

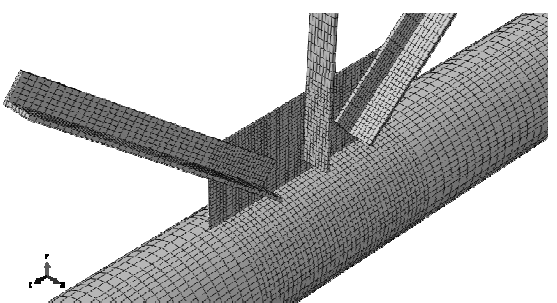

Fig. 6,Meshing of JD2

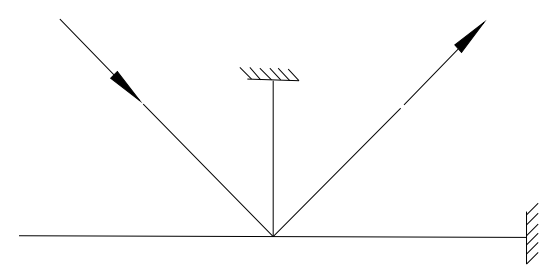

Fig. 8,Loading method

\section{Loading method}

According to the study of this article on k-joint of the actual force, this article select the boundary conditions and loading method that is tower column at one end and at the end of the bar multi constrained, exerting axial force along the web member [8]. Loading method shown in Fig. 8. 


\section{Analyses of the Results}

\section{Equivalent stress distribution curve}

Because of the intersection of tower column and web member formed a complex space curve, the radial stiffness of tower column and the axial stiffness of web member are very different, which is why the stress of tower column along radial and circumferential directions are uneven, usually larger points of stress concentration value in the node are called hot spots. Hot spots first reach yield, when continuing to load the point formed plastic zone and stress redistributed, the plastic zone continued to spread around [9].

To investigate the complex stress state and distribution rule and the stress development of the situation in the region, JD1 in tower column distance about $10 \mathrm{~mm}$ of web member roots around compression and tension select some measuring points; JD2, JD3 at root of gusset plate and distance tower column at the root of gusset plate about $10 \mathrm{~mm}$ around the node select some measuring points. According to the strain of the measuring points and yield strength, elastic modulus of the material, the complex stress condition of measuring point use Von-Mises equivalent stress to express. Using Von-Mises equivalent stress as the ordinate, measuring point number as the abscissa, the equivalent stress of measuring point at all load levels as a data series, and the wall of tower column to an equivalent stress distribution curve was obtained, measuring point positions and equivalent stress distribution curve of tower column as show in Fig. 9-14.

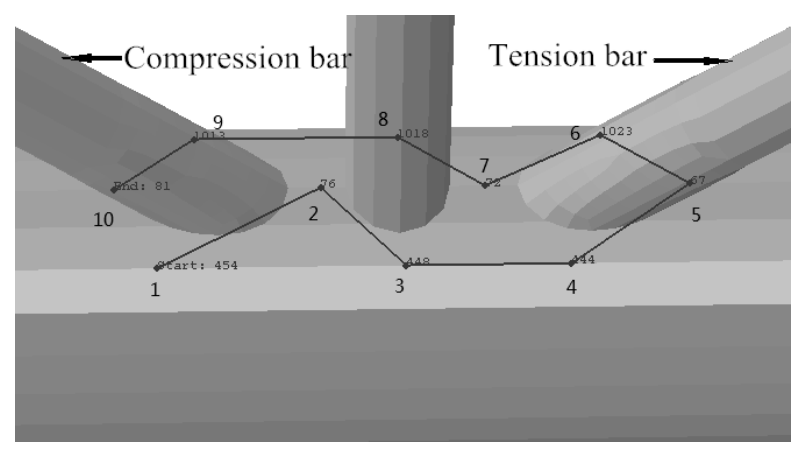

Fig. 9,Point layout of JD1

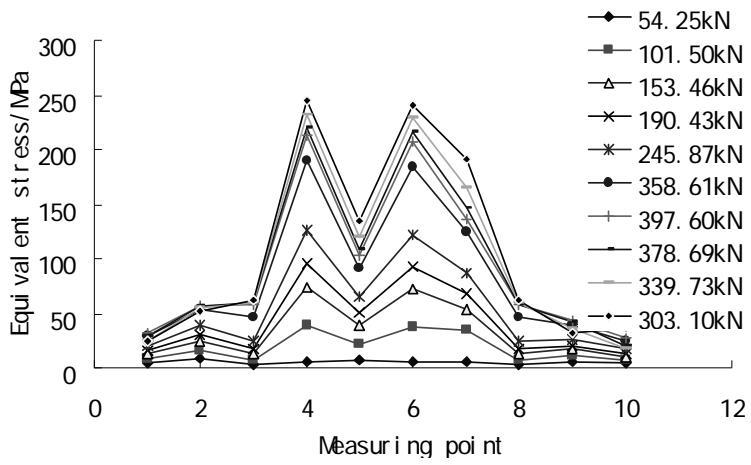

Fig. 10, Equivalent stress curve of JD1

From the tower column wall Von-Mises equivalent stress distribution curve of JD1, when JD1 reached ultimate bearing capacity, we can see the maximum equivalent stress of tower column wall measuring point is $212 \mathrm{MPa}$, and it did not reach the yield strength of the material and the wall of tower column remains elastic stage. The damage of node main is due to by pressure web member buckling under axis force caused unstable failure, and the equivalent stress of JD1 in 4 and 6 measuring points grow so fast that main is located in both sides of tensile inclined web member of tower column tube wall, and this reflect web member bearing capacity of their own in meeting requirements situation, and the damage region of JD1 easy occurs in both sides of tensile inclined web member of tower column tube wall. 


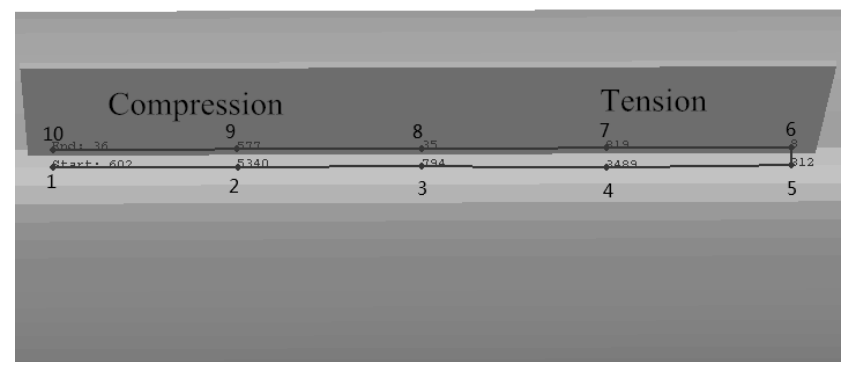

Fig. 11, Point layout of JD2

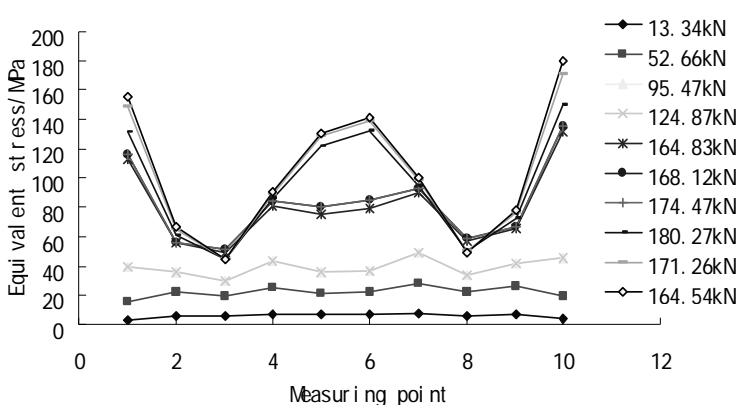

Fig. 12,Equivalent stress curve of JD2

From Fig. 11 and Fig. 12 we can see: the largest 10th measuring point equivalent stress of JD2 on the tower column tube wall reaches $180 \mathrm{MPa}$, tensile inclined web member with displacement increased to $164.54 \mathrm{kN}$ below, and gusset plate has yield in plastic stage. The stress of measuring point 1, 5, and 6 is larger and grow faster, mainly located in the two ends of gusset plates at the tower column wall, and this explains in the situation of the web member and gusset plates bearing capacity meeting the requirements, and the damaged region of JD2 easy occurs at connection of gusset plates two ends and tower column tube wall.

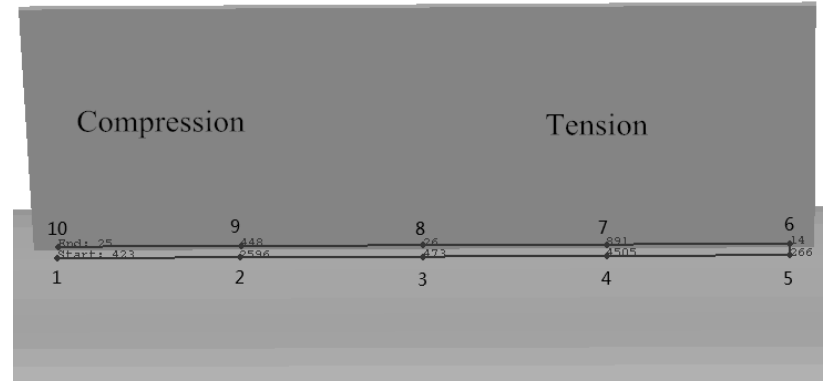

Fig. 13, Point layout of JD3

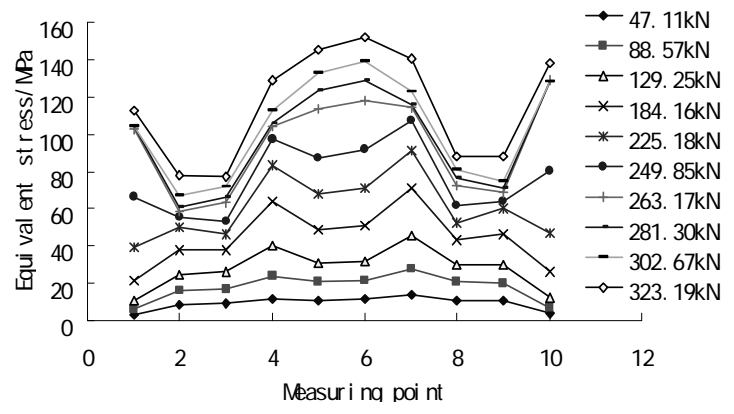

Fig. 14, Equivalent stress curve of JD3

You can see from Fig.13 and Fig.14: the largest 10th measuring point equivalent stress of JD3 on the tower column tube wall reaches $152 \mathrm{MPa}$, at this time the node gusset plates has entered into plastic stage. In addition, the stress of measuring point 1, 5, 6, 10 is larger and grow faster, mainly located in the two ends of gusset plates at the tower column wall, and this explains in the situation of the web member and gusset plates bearing capacity meeting the requirements, and the damaged region of JD3 and JD2 easy occurs in the connection of gusset plates two ends and tower column tube wall, easy happening tear failure.

\section{Bearing capacity}

By analysis the internal force of three web members form node, we can get the yield load, the yield displacement, ultimate bearing capacity and ultimate displacement of each node, as shown in table 2.

\begin{tabular}{ccccc}
\hline node & $\begin{array}{c}\text { yield } \\
\text { load/kN }\end{array}$ & Yield displacement $/ \mathrm{mm}$ & $\begin{array}{c}\text { ultimate } \\
\text { load/kN }\end{array}$ & $\begin{array}{c}\text { ultimate } \\
\text { displacement } / \mathrm{mm}\end{array}$ \\
\hline JD1 & 349 & 2 & 397 & 4.7 \\
JD2 & 146 & 1.2 & 180 & 5.5 \\
JD3 & 255 & 0.8 & 323 & 7.6 \\
\hline
\end{tabular}

Table 2, Load and displacement of every stage

You can see from table 2: in three web members form node, JD1 reach the ultimate load that is the 2.21 times of JD2 bearing capacity JD2 and 2.21 times of JD3, which reflect that the ultimate load of 
JD1 is the highest under the web member cross section area of the same situation. The damage of JD2 and JD3 are caused by buckling of gusset plates, but the ultimate bearing capacity of JD3 is the 1.8 times of JD2, and this is because of the JD3 web member using equal-leg double angle steel on both sides of the gusset plate and the web member of is single angle steel that is located in the single side of gusset plate, under axial force, JD2 gusset plate influenced by the eccentric additional moment, led to bending deformation, while due to the eccentric torsion effect of single angle steel pieces under pressure, led to gusset plate bent while also with torsional deformation. The main force state of JD3 gusset plate is axial pressure combined with the plane external bending moment, and this is also lead to the last destroy form of the gusset plane that is reason of outside the plane of drum curved failure.

\section{Conclusions}

By analysis the tower column tube wall Von-Mises equivalent stress distribution curve and ultimate bearing capacity of three web members form node, following conclusions can be drawn:

The equivalent stress curve distribution on the tower column tube wall is not uniform, and the stress larger and faster-growing region of JD1 concentrate in tower column tube wall both side of tensile inclined web member, and the larger and faster-growing stress region of JD2 and JD3 mainly occur in the connection of gusset plates two ends and tower column tube wall.

The three failure mode of web member node form: JD1 belong to unstable failure caused by the local buckling compression bar, JD2 and JD3 all belong to unstable failure caused by the local drum curved of gusset plates.

Under the situation of web member cross section area of the same, the ultimate load of JD1 is the highest than JD2 and JD3, and we recommend using web members form that is tubular joints of circular steel tube.

In the situation of the web member and gusset plates bearing capacity meeting the requirements, JD1 damage area is easily occurred in both sides of tensile inclined web member of tower column tube wall. JD2, JD3 in the connection of gusset plate's two ends and tower column tube wall are the weak part that is easy damaged.

For wind turbine tower of lattice type steel concrete, web member with important role of support in the mechanical process of whole system. So web joint welds design of member and tower is a key problem.

\section{References}

[1] Chang Chai, Manhua Song, Steel structure design and calculation, Mechanical Industry Press, (2006),6-10. (in Chinese)

[2] Fubin Gu, Xinwei Cui, and Weibin Ma, Discussion wind turbines with structure of concrete tower forms. Xinjiang agricultural university journal, (2009), 32(3), 82-85. (in Chinese)

[3] Linhai Han, Concrete-filled steel tube structure, Beijing Science Press, (2001), 64-74. (in Chinese)

[4] Zhongzhou Han, Research mechanical behavior on Lattice three-leg concrete filled steel Tubular column of wind turbine tower, Inner Mongolia University of science and technology, (2011), (in Chinese)

[5] Xingrong Li, Caiang Wei and Shikun Ding, Steel structure connection node Design Handbook (Second Edition). China architecture and building press, (2005), 349-426. (in Chinese) 
[6] Yiping Shi, Yurong Zhou, ABAQUS finite element analysis details, Mechanical Industry Press, (2006), 136-141. (in Chinese)

[7] Qianyi Song, Study on mechanical behavior of circular steel tube concrete-filled steel tubular k-joints, Tsinghua University, (2010). (in Chinese)

[8] Xingping Shu, Analysis and design of high steel structure, Science press, (2006), 212-241. (in Chinese)

[9] Yang Zhang, Research static behavior on square tube node the type of direct welded KT, Harbin industrial University, (2006). (in Chinese) 